\title{
THE NATURE OF LINGUISTIC PROCESSES DETERMINING THE APPLICABILITY OF NOMINALIZATIONS APPLIED TO STRINGS NP-COP-AP
}

\author{
ANNA UNISZEWSKA \\ University Gdansk
}

\begin{abstract}
The article aims at analyzing the principle which determines the acceptability and correctness of nominalizations performed upon sentences of the type: NP-Cop-AP. The discourse was initiated by Chomsky (1972), who demonstrated the fact that the correctness of $T_{\text {NOM }}$ is established by processes taking place in SS, thus suggesting that the analysis of SS might shed light on the nature of the underlying DS processes. This view was lated supported by evidence coming from the analysis of the lexical features of NP and AP, carried out by Postal (1974). Thus discussion was initiated as to the role of 'the lexicalist hypothesis' and 'lexicalism' in sentence derivation.

The author of the article discusses the validity of 'the lexicalist hypothesis', which maintains that lexical features alone can suffice for the explanation of the acceptability of $T_{\text {NOM }}$ applied to strings NP-Cop-AP. She claims that the resort to the lexical features needs to be made with respect to, as she calls them, elliptic structures, i. e. structures with shifted designations.

In the search for the rule determining the correctness of $\mathrm{T}_{\mathrm{NOM}}$, the author considers such principles as: Chomskean observation of its dependence upon the 'rough similarity' between SS and DS (Chomsky 1972), Postal's analysis of agentivity (Postal 1974), the role of the antecedent of the implied subject of the infinitive phrase (whenever it is contained in such structures) and, as she calls it, $T_{\text {NOM-Over- }} \mathrm{T}_{\text {NOM }}$ principle. The analysis leads to the conclusion that the acceptability of $\mathrm{T}_{\mathrm{NOM}}$ can be assumed to be determined by the syntactic process. The author names it $\mathrm{T}_{\mathrm{NOM}^{-}}$ over- $\mathrm{T}_{\text {NOM }}$ constraint and analyzes it on the selected corpus of English and Polish sentences.
\end{abstract}

As the theory of generative grammar developed, Chomsky realized the fact that the observation of surface structure (SS) can significantly contribute to the understanding of the underlying deep structure (DS) (Chomsky 1972:104). This concept was analyzed on the example of nominalizing transformations applied to sentences:

John is certain that Bill will leave.

John is certain to leave.

It was noticed that while $\mathrm{T}_{\mathrm{NOM}}$ can be applied to the first sentence, with the resulting nominal phrase: 
John's certainty that Bill will leave,

it was not possible to do the same with the latter: the $\mathrm{T}_{\mathrm{NOM}}$ renders the resulting phrase:

*John's certainty to leave,

ungrammatical. Chomsky offered the explanation of this phenomenon in terms of the influence which the sequencing of units in the surface structure has on the applicability of this transformation. In other words, as Chomsky suggested, whenever the lay-out of constituents in SS roughly corresponded with the layout of corresponding markers in DS, the $\mathrm{T}_{\text {NOM }}$ produced a grammatical phrase. On the other hand, if SS was markedly different from DS, the phrase resulting from the application of $\mathrm{T}_{\mathrm{NOM}}$ was ungrammatical.

The concomitant of this observation is that the correctness of the nominal phrase is determined by the position of grammatical subject with respect to the corresponding logical subject. This observation reveals that, whenever the grammatical subject (i.e. a unit occupying a pre-verbal position in SS) required that in the underlying kernel sentence its logical counterpart takes on the postverbal position, $T_{N O M}$ violates grammaticality. Hence the assumption was formed that whether NP takes on either pre- or post-verbal position in DS, has to be related to the presence of a feature [+Agent] marking this NP (Postal; 1974:53-54). In DS, NP marked as [+Agent] has to take on the pre-verbal position, i.e. the position of a subject, and, conversely, NP marked as [-Agent] takes on the post-verbal position, i.e. the position of an object. This clearly implies that the process of terminal string derivation which underlies a surface structure, is determined by lexical markers adjoining subsequent symbols in a string. Semantic interpretation interferes with the organization and lay-out of the terminal string.

This view was later undermined by Chomsky (1975) who noticed structural affinity passive statements shared with kernel strings NP-Cop-AP.

It can hardly be accidental that the English passive makes use of the copula and that the verb morphology is so clearly analogous to certain adjectival constructions. This fact may well find its place within a theory of surface-structure semantic interpretation, making essential use of the subject-predicate constructions in surface structure, the theory of traces, and other related ideas. We have been operating so far on the assumption that surface structure alone undergoes semantic interpretation. But there are some obvious objections to this conjecture (Chomsky 1975:114-116).

Chomsky in his earlier project of the theory of government and binding (GB) (Chomsky 1981) diminished the role of the lexicalist hypothesis in sentence 
derivation, reckoning NP-movement transformational; and thus characterized as syntactic, not lexical process.

If we consider $\mathrm{GB}$, it is apparent that there is a sense in which, with respect to the treatment of NP-movement relationships, it is the most conservative of the theories we are mainly considering here [generalized phrase structure grammar - GPSG, lexical-functional grammar - LFG, relational grammar RG - author's remark] (McCloskey 1988:49).

Still even in his cautious approach towards acknowledging the role of the lexicalist hypothesis in linguistic processes, Chomsky reckoned the significance of theta roles in the functioning of such operations as NP-movement.

The 'Lexicalist Hypothesis', to oversimplify somewhat, is the claim that a certain amount of what is usually regarded as 'syntax' is actually done in the lexicon, logically 'preceding' the application of any strictly syntactic rules; transformations. ... all versions of Chomsky an theory since the early 70's assume some version of it .... Indeed, REST has been getting increasingly 'lexicalist' in recent years (Tauber, jtauber.com).

The question arises whether the labelling of respective units in a string NP-CopAP with lexical markers is crucial for determining the applicability of $T_{\text {NOM }}$. The analysis might help alleviate the feeling of uneasiness posed by friction resulting form REST being constantly confronted with 'lexicalist' solutions offered, for example, by LFG.

The analysis proposed here will take the following corpus of English sentences and their Polish equivalents into account.
(1) The raven is tamed.
(2) The cat is fluffy.
(31) Peter is annoying.
(4) Garlic is healthy.
(51) The car is easy to repair.
(61) The door is open.
(71) The wheel is spun.

(1 $\left.{ }_{2}\right)$ Kruk jest oswojony.

(2) Kot jest puszysty.

$\left(3_{2}\right)$ Piotr jest denerwujacy.

$\left(4_{2}\right)$ Czosnek jest zdrowy.

$\left(5_{2}\right)$ Samochód jest latwy do naprawienia.

$\left(6_{2}\right)$ Drzwi sq otwarte.

$\left(7_{2}\right)$ Kolo jest obracane.

All sentences represent the type NP-Cop-AP. (1) and (2) differ only in that in (2) Past Participle is used (Chomsky claimed (1975:114) that this difference is negligible on the level of deep structure). Interestingly enough, with respect to both (1) and (2), the application of $\mathrm{T}_{\mathrm{NOM}}$ renders strings:
I $\left(1 \mathrm{a}_{1}\right)$ tameness of the raven
$\left(1 \mathrm{a}_{2}\right)$ oswojenie kruka
$\left(2 a_{1}\right)$ fluffiness of the cat
$\left(2 \mathrm{a}_{2}\right)$ puszystość kota 
well-formed. On the other hand, the same transformation $T_{\text {NOM }}$ violates the well-formedness of (3), (4) and (5):

\section{II $\left(3 \mathrm{a}_{1}\right)$ *Peter's annoyingness $\left(4 \mathrm{a}_{1}\right) *$ healthiness of garlic $\left(5 \mathrm{a}_{1}\right)^{*}$ easiness of car's repair}

$\left(3 \mathrm{a}_{2}\right)$ *denerwujacość Piotra

$\left(4 \mathrm{a}_{2}\right) * z d r o w o s ́ c ́ ~ c z o s n k u$

$\left(4 \mathrm{a}_{2}\right)$ *latwość naprawienia samochodu

though $\left(4 a_{2}\right)$ may seem dubious in this respect. For the native speaker of Polish this sentence probably seems acceptable, giving rise to the conjecture that its grouping in the set of unacceptable nominalizations might not be justifiable. This will become the matter of further analysis.

The nominalization of (6) and (7) leads to the formation of grammatical nominal phrases, likewise:
III $\left(6 \mathrm{a}_{1}\right)$ the openness of the door
$\left(6 \mathrm{a}_{2}\right)$ otwarcie (sie) drzwi
$\left(7 a_{1}\right)$ the spinning of the wheel
$\left(7 \mathrm{a}_{2}\right)$ obracanie (sie) kola.

with the implication that these sentences both in English and in Polish require reflexivity for the correct handling of transformational processes related to them. (In English they would be sentences of the type NP-V - -Complement: The door opened itself. The wheel spins itself.)

The above examples, grouped in I, II, and III, cast doubt on the assumption that the acceptability of $\mathrm{T}_{\mathrm{NOM}}$ corresponds to agentivity. Out of all phrases subjected to $\mathrm{T}_{\mathrm{NOM}}$, only the NP in (3), (group II) was marked as [+Agent] beyond any doubts. Interestingly enough, it featured in the group which also contained a NP marked as [-Agent] (5).

Yet one more observation to make regarding group II is that all sentences contained in this group are elliptic. Say, in (4) Garlic is healthy AP does not assign a certain property to the object designated by NP, i. e. to garlic, but, instead, implicitly describes the state which, in itself, is the consequence of the fact that someone eats garlic. Thus the state or property designated by AP in this sentence accompanies a certain activity, which albeit, not mentioned in the sentence itself, is the necessary premise on which the understanding of this sentence rests. This shows that the understanding of this sentence is built on anticipatory processes, wherein the mind on hearing the sentence moves from what is explicit in it, back to the set of implicit premises necessary for the formation of the meaning of this sentence. The process at work can be visualized as follows:

PREMISE 1: the first stage of the anticipatory process at work in deep structureconstitution of the sentence's meaning: the sentence interpreted as a conclusion in the syllogism:

$\begin{array}{ccc}\text { NP } & \text { Cop } & \text { AP } \\ I & \text { am } & \text { healthy }\end{array}$


PREMISE 2: the second stage of the anticipatory process involved in meaning constitution: the mediating sentence linking the fact expressed above with the fact that a certain activity is performed

$\begin{array}{lll}\mathrm{NP}_{1} & \text { Cop } & \mathrm{NP}_{2} \\ l & \text { eat } & \text { garlic }\end{array}$

The speaker in forming sentence (4) has to be aware of the fact that the mental process leading to the constitution of meaning involves the anticipation of both premises. The speaker also has to anticipate the fact that the passing through stage 2 requires that the sentence be passivized:

$\mathrm{T}_{\text {pass }}$ Garlic is eaten.

It is only in this form that the sentence will enable to pass on to the next stage of the ellipsis-derivation, where garlic features as subject, not the object:

Garlic is healthy.

The same staging in the sentence derivation can be attributed to sentence (3). It thus takes on the form of the following syllogism (where, again, just as it was before, both - passivization and substitution processes are involved):

\section{PREMISE 1: $\quad$ I am annoyed. \\ PREMISE 2: $\quad$ I talk to Peter.}

CONCLUSION: Peter is annoying.

My annoyance reveals itself as a result of an implicitly 'bracketed' activity undertaken with Peter. When it comes to the third sentence set in this group, the car is easy to repair, there is also a shift of the attributive function of AP (easy). While SS 'attributes' it to the car, DS reveals that easy should be attributed to a certain fact expressed as:

[for smn [to repair the car]] is easy.

The above analyses were made in the way that emphasized the semantic aspect of the sentence constitution. The question arises whether the analysis carried out from this angle is plausible enough for the explanation of linguistic facts, i.e. whether it can be considered to have the explanatory capacity for all possible occurrences of barred nominalizations.

Yet another problem arises concerning the very nature of the semantic analysis, i.e. to what extent it adopts the mode of explanation similar to that 
which helps cognize extralinguistic phenomena. In other words, does semantic analysis allow for linguistic processes involved in the forming and understanding of meaning to be clearly told apart from the underlying psychological processes, which take place whenever something is being asserted about the world? The uniformity of categorization of both the world and language implies principal affinity between apriori rules involved in world perception and apriori rules involved in sentence perception. However tempting (mainly due to its simplicity) this view may be, it seems entirely unsubstantiated. The belief that both the phenomenal world and the world of concepts are divinely preordained (to use Lebniz's terminology) seems too far-fetched to pass the test of scientific validity. The danger of a linguist getting entangled in psychological processes which constitute human ability to cognize the world can be illustrated on the example of sentences from group III where, in fact, it seems dubious if the linguist's decision as to whether treat the door and the wheel as marked [+Agent] or [Agent], is truly determined by intrinsic linguistic processes, and not - by the way human beings perceive phenomena. As James Tauber remarked,

in the 'real world' do things rotate or are they rotated? [If] such patterns are linguistically imposed, ... we are dealing with facts about linguistic pattems, not about 'real world' phenomena ... after all it's primarily (human) language we are claiming to study here, not physics. We are dealing here not only with the relationship between human language and phenomenal (i.e. 'real world) reality but that between human language and human cognition, i.e. how we as human beings perceive phenomenal reality (Tauber, jtauber.com).

Taking this into account one might doubt whether the marker [+/- Agent] can be plausibly used as a criterion for differentiating between acceptable and unacceptable nominalizations. If so, the very decision as to which utterances are acceptable, would be determined rather by psychological, not linguistic processes.

With regard to the elliptic sentences analysed before, it is unclear how to 'delineate' the class of sentences which require for their understanding the application of anticipatory processes and tell them apart from sentences which do not. If we assume that for the understanding of the elliptic structures of the type grouped in II, a certain set of premises stated as implied sentences is required, it turns out that practically for every sentence it is possible to find a correspoding anticipatory action which, so to say, 'enhances' its understanding:

(8) The book is interesting - anticipated premise: [PRO to read t];

Ksiqzika jest ciekowa (w czytaniu)

(9) Garlic is healthy - anticipated premise: [PRO to eat];

Czosnek jest zdrowy (do jedzenia)

(10) Peter is hungry - anticipated premise [PRO to eat];

Piotr jest glodny (w jedzeniu) 
The process of selection of elliptic structures based on the logical criterion which states that for any elliptic structure the corresponding anticipatory structure which significantly contributes to its meaning (or without which the understanding of its meaning would be barred) has to be found, seems, therefore, ineffective. The speaker's decision as to where the anticipatory structure is necessary, and where it merely 'enhances' what is already clearly stated in the analyzed sentence, cannot be subjected to unequivocal logical procedure, and thus, becomes a matter of tenuous, hardly tangible and quite recondite considerations. It is no longer the matter of logic.

With respect to the set above $((8),(9),(10))$ it can be noticed that in (8) and (9) the null subject PRO of the embedded phrase does not have its antecedent in the main subject. In other words, the movement from PRO (implicit subject of infinitive clauses) to the main subject is barred:

(8a) The book is interesting [PRO to read t], where movement from PRO to the book is barred and, respectively, $T_{\text {NOM }}$ is barred:

(8b) *the book's interest,

(9a) Garlic is healthy [PRO to eat t], where movement from PRO to garlic is barred, and so is $\mathrm{T}_{\text {NOM: }}$ :

(9b) *garlic's healthiness

On the other hand, the implicit subject of the infinitive phrase in (10) has its antecedent in the main subject:

(10a) Peter is hungry [PRO to eat]. Here movement from PRO to Peter is allowed and $\mathrm{T}_{\mathrm{NOM}}$ is allowed, likewise:

(10b) Peter's hunger

The same works for:

(11) Peter is willing [PRO to help others], thus yielding the acceptable nominalization: (1 1a) Peter's willingness [PRO to help others].

This procedure, however, fails to account for the unacceptability of structures such as:

(12) Peter is annoying [PRO behaves in a certain way]

$\left(12_{2}\right)$ Piotr jest denerwujacy (w swoim zachowaniu),

where, although implicit PRO is properly bound by its antecedent, the nominalization is barred:

$\left(12 \mathrm{a}_{1}\right) *$ Peter's annoyingness, 
The same can be, conversely, showed in

(13) The task is easy [PRO to do t].

where the implicit PRO is not bound by the main subject and still the $\mathrm{T}_{\mathrm{NOM}}$ yields the correct structure:

$\left(13 \mathrm{a}_{1}\right)$ the easiness of the task $\quad\left(13 \mathrm{a}_{2}\right)$ tatwośc zadania.

From the above considerations the conclusion has to be drawn that the analysis of structures in terms of allowability of $T_{\mathrm{NOM}}$, cannot be based on the following criteria:

(a) agentivity of the NP functioning as the main subject (Postal 1974:53-54),

(b) similarity of SS and the corresponding DS (Chomsky 1972:104),

(c) the presence of anticipatory semantic processes involved in the understanding of the sentence,

(d) the relatedness of the implicit PRO to its main subject antecedent.

For each of the mentioned criteria it was possible to find an example defying its plausibility and universal applicability.

It may still, however, be possible to uphold the view that the notion of ellipsis will help understand sentences in which the clarity of the message becomes blurred as a result of the applied shift in designation (i.e. the fact that the role of feature attribution taken on by AP, allows AP to move more or less freely from its own object to other objects holding semantic ties with it) just as it was in Garlic is healthy. This would corroborate the assumption that the understanding of the sentence rests on the analysis of selectional features in the way that whenever a shift of attribution is performed, say, in:

$\left(15_{1}\right)$ Crops are ready for harvesting

$\left(15_{2}\right)$ Zboże jest gotowe do zbioru

where the implied meaning is represented in the ellipsis:

$\left(15 \mathrm{a}_{1}\right)$ Crops are ripe

Farmers are ready for harvesting

Crops are ready for harvesting

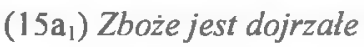

Rolnicy sa gotowi do zbioru

Zboże jest gotowe do zbioru

it must be possible for the hearer to trace the linguistic process up to the point where 'kernel designations' (i.e. the fact that ready characterizes farmers, not crops, and vice versa, ripe characterizes crops, not farmers) for particular linguistic units are retrieved. However, the applicability of $\mathrm{T}_{\mathrm{NOM}}$ is dependent on 
the process which is intrinsically syntactic. The syntactic rule governing this transformation may be referred (by analogy to A-over-A principle; Chomsky $1972: 52$ ) to as $T_{\text {NOM-Over- }} T_{\text {NOM }}$ constraint. It stipulates that double nominalizations are barred. Thus from

The car is repaired,

it is possible to derive nominal phrase

the car's repair, but from

The car's repair was easy,

it is no longer possible to derive

*the easiness of car's repair.

This explanation would account for the fact that the legitimacy of its Polish equivalent latwość naprawienia samochodu seems less dubious. Polish, by means of inflection, allows for such structures to retain their clarity in spite of the fact that they entail double nominalization.

\section{REFERENCES}

Chomsky, N.A. (1972): Language and mind. New York: Harcourt Brace Jovanovich.

Chomsky, N.A. (1975): Reflections on language. New York: Pantheon

Chomsky, N.A. (1981): Lectures on government and binding. Dordrecht: Foris

Chomsky, N.A. (1986): Barriers. Cambridge MA: MIT Press.

McCloskey, J. (1988): Syntactic theory. In: F.J. Newmeyer (eds.), Linguistics: The Cambridge survey. Cambridge: CUP.

Postal, P. (1980): The domain of syntax. Translated as: P. Postal, Domena sktadni. In: B. Stanosz (ed.), Język $w$ swietle nauki.Warszawa: PWN.

Tauber, J. Synthinar: The syntactic theory seminar. jtauber.com. 